University of Warwick institutional repository: http://go.warwick.ac.uk/wrap This paper is made available online in accordance with publisher policies. Please scroll down to view the document itself. Please refer to the repository record for this item and our policy information available from the repository home page for further information.

To see the final version of this paper please visit the publisher's website. Access to the published version may require a subscription.

Author(s): MacCallum, Fiona; Keeley, Sarah

Article Title: Embryo donation families: A follow-up in middle childhood Year of publication: 2008

Link to published version: http://dx.doi.org/10.1037/a0013197

Publisher statement: 'This article may not exactly replicate the final version published in the APA journal. It is not the copy of record'. 


\section{EMBRYO DONATION FAMILIES: A FOLLOW-UP IN MIDDLE CHILDHOOD}

Fiona MacCallum, Department of Psychology, University of Warwick; Sarah Keeley, University of Warwick

This study was funded by Economic and Social Research Council Grant RES-000-221740. We are grateful to all the parents and children who participated in the study. We also thank Bourn Hall Clinic, Sheffield Fertility Centre, Manchester Fertility Services, the Assisted Conception Unit at St James's Hospital, and Bedfordshire, Hertfordshire, and Surrey Social Services for their help in recruiting families.

Correspondence concerning this article should be addressed to Fiona MacCallum, Department of Psychology, University of Warwick, Coventry, CV4 7AL, UK. Email: Fiona.Maccallum@warwick.ac.uk. 


\begin{abstract}
Couples who conceive using donated embryos rear a child to whom they are genetically unrelated. It has been suggested that this may have negative consequences for parenting and child development. Findings are presented of the second phase of an exploratory study of families with a child conceived through embryo donation. Seventeen embryo donation families with a 5-9 year old child were compared with 24 adoptive families and 28 in vitro fertilisation families. The quality of the mother's parenting, and the child's social and emotional development were assessed using standardised interviews and questionnaires administered to mothers and teachers. Embryo donation children were not at increased risk of psychological problems during middle childhood and the families were generally functioning well. However, higher emotional over-involvement of embryo donation parents was found, along with more reluctance to disclose the method of family creation. These preliminary findings are discussed in terms of implications regarding the importance of genetic and gestational relationships between parents and children.
\end{abstract}


Since the birth of the first IVF baby nearly 30 years ago (Steptoe \& Edwards, 1978), the number of couples using assisted reproductive techniques (ARTs) has steadily increased. By 2002, approximately one in every 100 babies born in the US was conceived through ARTs (American Society for Reproductive Medicine, 2008). Furthermore, in the UK in 2004 nearly 30,000 couples attempted fertility treatment, a three-fold increase on the frequency in 1991 (HFEA, 2005). One form of ART is embryo donation, where an embryo created by the gametes of one couple is donated to another couple who then rear the resulting child. Unlike straightforward IVF, embryo donation was developed more recently and is less frequently used, with an average of $\sim 35$ embryo donation children born per year in the UK over the last decade (HFEA, personal communication). Concerns have been raised about the potentially adverse psychological consequences of this new method of family formation, but very little research has investigated the experiences of embryo donation families.

Conceiving a child using donated embryos results in a family structure where the child is not genetically related to either parent, paralleling that seen in adoptive families. Adoption presents children with specific psychological tasks including coping with the knowledge that they are adopted, and incorporating this awareness into a coherent sense of identity (Triseliotis, Shireman, \& Hundleby, 1997). Outcomes for the psychological development of adopted children are mixed. Non-clinical studies of adopted children do not find them to be at risk of problems with temperament or development in infancy and early childhood (Carey, Lipton, \& Myers, 1974; Plomin \& DeFries, 1985). However, in middle to late childhood, some adoptees exhibit higher levels of psychological maladjustment than nonadoptees (Brand \& Brinich, 1999). One possible explanation for this is that problems emerge at this stage due to the child's growing understanding of the concept of adoption, and their resulting feelings of loss (Singer, Brodzinsky, \& Braff, 1982). Embryo donation children may 
exhibit similar problems during this period if they also feel a sense of the loss of their genetic parents

However, this loss will be consciously felt only if embryo donation children are aware that they are not their social parents' genetic offspring. A key issue relating to families with children conceived using donated gametes (sperm or eggs) is that historically the majority of couples have not disclosed the facts about the conception to the child. One review of studies of donor insemination families found that only between $1 \%$ and $20 \%$ of parents intended to tell their child about their genetic origins (Brewaeys, 2001). A study of egg donation families found slightly higher disclosure rates but still just $29 \%$ of couples were definitely planning to tell the child (Murray \& Golombok, 2003). In contrast, adopted parents as a rule begin to communicate about the adoption from an early age (Brodzinsky, Smith, \& Brodzinsky, 1998). In the last 20 years, there has been growing disquiet about the possible adverse effects of secrecy in gamete donation, particularly on family relationships and the child's psychological well-being (Baran \& Pannor, 1993; Daniels \& Taylor, 1993). The consequence has been a worldwide climate shift towards increasing openness, such as the UK legislation implemented in April 2005 allowing donor conception offspring access to the donors' identity. This is reflected in the attitudes of a sample of gamete donation parents with children conceived after 1999 , where $46 \%$ of donor insemination parents and $56 \%$ of egg donation parents reported that they planned to disclose the conception to their child (Golombok, Lycett et al., 2004); a marked increase on previous research. It is not yet known how embryo donation parents will behave with respect to disclosure.

An alternative explanation for the adjustment problems of adopted children relates to the lack of genetic links in the family. Evolutionary psychology suggests that parental investment in children is significantly affected by the genetic relationship (Bjorklund, Younger, \& Pellegrini, 2002). From this perspective, the absence of a genetic link may result 
in less emotional investment in the child, and subsequently less positive parenting. According to attachment theory, factors related to quality of parenting, such as parental sensitivity, help determine the nature of the attachment formed by the child to the parents (Ainsworth, Bleher, Waters, \& Wall, 1978; De Wolff \& van IJzendoorn, 1997). These child-parent relationships are in turn hypothesised to be the most prominent influence on the child's future mental health development (Bowlby, 1988). Thus, if parenting a non-genetic child, whether conceived through embryo donation or adopted, affects parenting processes, there may be negative consequences for both family functioning and child outcomes.

Previous research on gamete donation families has found no evidence to suggest that either the quality of parenting or children's psychological development is adversely affected by the absence of a genetic link between one parent and the child (Golombok, Lycett et al., 2004). However, in donor insemination or egg donation families, the presence of one genetic parent could facilitate the relationship between the child and the other parent. Therefore, embryo donation families may more closely resemble adoptive families. Despite the elevated rates of psychological problems seen in some adoptees, research shows that in the majority of adoptive families, positive parent-child relationships prevail (Levy-Shiff, Goldshmidt, \& HarEven, 1991; Plomin \& DeFries, 1985). This is particularly true when children are adopted in infancy, the situation most similar to embryo donation (Hoopes, 1982; Singer, Brodzinsky, Ramsay, Steir, \& Waters, 1985).

Embryo donation has one fundamental difference to adoption; there is a biological link to the mother through gestation. Thus, parents have the opportunity to bond to the child prenatally, and to regulate the pre-natal environment. Some view the gestational link as equal in importance to the genetic link (Mahowald, 2000). Mothers can form a prenatal attachment to the foetus (Laxton-Kane \& Slade, 2002), which has been found to show some modest but significant association with postnatal infant attachment styles (Muller, 1996). Therefore, the 
gestational relationship in embryo donation may promote more positive parenting than is seen in adoptive families.

To explore whether the gestational link influences parenting and family functioning, embryo donation families were compared to families with a child adopted in infancy (MacCallum, Golombok, \& Brinsden, 2007). A second comparison was made to families with children conceived through IVF using the parents' own gametes to examine the effect of genetic relationships. This group was favoured over natural conception families to control for the experience of infertility and the use of high-tech ARTs, which may themselves have consequences for parenting (Burns, 1990; van Balen, 1996). The first phase of the study was conducted when the children were aged 2-5 years. All parents were heterosexual couples who were married or co-habiting at the time of the child's conception. The three family types did not differ in the quality of parenting provided, although the embryo donation parents were found to score higher on measures of emotional over-involvement, and were significantly less likely to disclose the method of family creation. During early childhood, the embryo donation children were not showing raised levels of psychological problems.

This article reports on a follow-up of these families as the children reach middle childhood. The follow-up was conducted firstly because this was one of the only samples worldwide of embryo donation parents and children to be studied from a psychological viewpoint. Continuing research allows exploration of whether the psychological processes operating in these families change over time. Aspects where embryo donation families differed previously, such as emotional over-involvement of parents may become more problematic as children require increased independence. Also, any existing problems in child development that were not perceptible in the preschool period may become more apparent when children reach school age. Secondly, middle childhood is the stage at which problems in psychological development emerge for some adopted children. It may be that the elevated 
rates of difficulties in adoptees are due to adoption-specific characteristics, such as the growing awareness of the relinquishment by birth parents (Singer et al., 1982), or the experience of non-optimal prenatal and preplacement environments (Brodzinsky et al., 1998). If so, embryo donation children would not be expected to show the same increase. On the other hand, if problems of adopted children are directly related to a lack of genetic relationships in the family resulting in lower quality parenting as would be predicted by evolutionary psychology (Bjorklund et al., 2002), similar patterns would be predicted for embryo donation children. Finally, the families were first seen prior to 2005, since when UK law regarding openness in donor conception has changed. The follow-up study allows an investigation of whether this change was reflected in any shift in the attitude of embryo donation parents. Therefore, the aim of the study was to compare quality of parenting, child development, and current patterns of disclosure across the three family types.

\section{Method}

\section{Participants}

During the first phase of the study, parents were asked for permission to contact them in the future (for recruitment details, see MacCallum et al., 2007). Consenting families were contacted either by telephone or letter when the target child was aged between 5 and 10 years. Seventeen families with a child conceived by embryo donation (4 families had twins), 24 families with an adopted child (all singletons) and 28 families with a child conceived by IVF (9 families had twins) agreed to take part in the follow-up. In total, two embryo donation, three adoptive and two IVF families withdrew, 2 embryo donation families could not be traced and one adoptive family had emigrated. Cooperation rates were $81 \%, 86 \%$ and $93 \%$ for the embryo donation, adoptive and IVF families, respectively. Non-participating families did not differ from participating families on the data collected in the first phase. 
There were similar proportions of male and female target children in each group $(51 \%$ female), and no group differences were found for family size ( $88 \%$ of the target children had one sibling or none) or birth order (68\% of target children were first born). Family types did not differ on social class, rated according to the Registrar General's Classification (OPCS and Employment Department Group, 1991) taking the highest ranking occupation of either parent, with $71 \%$ of parents having a professional or managerial role. Marital status did not differ between groups; two embryo donation and four IVF couples had separated since the child's conception, and one IVF mother had died.

There were significant group differences in the age of the mothers, $F(2,65)=8.53, p$ $<.01$, and the age of the target child, $F(2,66)=16.28, p<.001$. The embryo donation mothers were oldest ( $M=47$ years), the IVF mothers were youngest ( $M=40$ years) and the adoptive mothers fell in between $(M=43$ years $)$. Regarding the children, the adopted children were oldest ( $M=95$ months) followed by the embryo donation children ( $M=93$ months), with the IVF children youngest $(M=77$ months). Fathers' ages did not differ between family types $(M=45$ years). The demographics showing group differences (mother's age and child's age) were included in future analyses as covariates.

\section{Procedure}

Ethical approval for the research was granted by the Humanities and Social Sciences Research Ethics Committee at the University of Warwick. Data were collected from the mother using interviews conducted in the family home by a researcher trained in the study techniques (where the mother was deceased, the father was interviewed). Interviews took 4590 minutes and were digitally recorded. Seventy-seven percent of mothers completed standardised questionnaires regarding their marital and psychological state, and their child's socio-emotional development. There were no differences between groups in the proportions of questionnaires returned. Nor was there a difference on the interview measures between 
those who returned questionnaires and those who did not, suggesting that is not necessarily those experiencing more problems that are providing less information.

\section{Measures}

\section{Mothers’ Marital and Psychological State}

Mothers were administered the Golombok Rust Inventory of Marital State (GRIMS: Rust, Bennum, Crowe, \& Golombok, 1988; Rust, Bennun, \& Golombok, 1990), a questionnaire assessing the quality of the marital relationship. The short-form of the Parenting Stress Index (PSI/SF: Abidin, 1990) was used to determine the level of stress mothers experienced specifically within the parenting role. To assess anxiety and depression mothers completed the Trait Anxiety Inventory (TAI: Spielberger, 1983) and the Edinburgh Depression Scale (EDS: Cox, Holden, \& Sagovsky, 1987; Thorpe, 1993), respectively. All four of these questionnaires have been shown to demonstrate good reliability and validity and to discriminate successfully between clinical and non-clinical populations. For each instrument, higher scores represent higher levels of problematic behaviours.

\section{Quality of Parenting}

An adaptation of a semi-structured standardised interview designed to assess quality of parenting (Quinton \& Rutter, 1988) was used to gain information about the mother-child relationship. Detailed descriptions were obtained about mother-child interactions, the child's behaviour, and the mother's response. The validity of this interview schedule has been shown by a high level of agreement between observational ratings of mother-child relationships in the home and interviewer ratings (Quinton \& Rutter, 1988). The interview was rated using a comprehensive coding manual and regular research team meetings were held to ensure rater consistency. Inter-rater reliability was calculated by having approximately $40 \%$ of the interviews rated from recordings by a second researcher, who was "blind" to family type (as 
far as was possible, because parents sometimes referred spontaneously to family type during the parts of the interview being coded).

The following individual variables were rated from the interview: (1) mother's enjoyment in play, rated on a 4-point scale (0-3) from "little or none" to "a great deal", which assessed how much the mother expressed enjoying engaging in age-appropriate leisure activities with her child; (2) ease of bedtime, rated on a 5-point scale (0-4) from "no difficulty" to "major battles", which assessed the level of difficulty the mother reported in getting their child to bed; (3) frequency of disputes, measuring how often mother-child conflict occurred over a 3 month period; (4) level of battle, rated on a 4-point scale (0-3) from "no confrontations" to "major", which assessed the intensity of these disputes; (5) overall supervision whilst playing out, rated on a 5-point scale (0-4) from "not allowed out without an adult" to "generally poor", which measured the degree of parental supervision of the child when playing outdoors; (6) chaperonage, rated on a 7-point scale (0-6) from "not allowed out without an adult" to "allowed to play with unknown children, territory undefined", which assessed how much freedom the child is given when playing with others; and (7) enjoyment in motherhood, rated on a 4-point scale (0-3) from "none" to "a great deal", which assessed the level of joy expressed by the mother regarding parenting. Pearson product-moment interrater reliability coefficients for these individual variables were 0.94 (mother's enjoyment in play), 0.83 (ease of bedtime), 0.96 (frequency of disputes), 0.84 (level of battle), 0.83 (supervision when playing out), 0.91 (chaperonage), and 0.80 (enjoyment in motherhood).

Overall ratings of the quality of parenting were also made using strict coding criteria, and taking into account all information gathered in the interview. These were: (1) expressed warmth, rated on a 6-point scale (0-5) from "none" to "high". Aspects of maternal warmth included how warmly the mother spoke about the child (including her tone of voice), spontaneous expressions of warmth, sympathy and concern expressed about any difficulties 
the child may have, and interest in the child as an individual; (2) emotional over-involvement, rated on a 4-point scale (0-3) from "none" to "enmeshed", which took into account the extent to which family life was focused on the child, how overprotective or over-concerned the mother was regarding the child, and whether the mother had interests or activities not involving the child; and (3) sensitive responding, rated on a 5-point scale (0-4) from "none" to "very sensitive responding", which assessed to what degree the mother could recognise, and respond appropriately to, her child's fears, worries and anxieties. Inter-rater reliability coefficients for the three overall variables were; 0.80 (expressed warmth), 0.85 (emotional over-involvement) and 0.82 (sensitive responding).

\section{Children's Socio-emotional Development}

The Strengths and Difficulties questionnaire (SDQ: Goodman, 1994, 1997) for 4-16 year olds was administered to the mother and, with mothers' permission, the child's teacher. Seventyseven per cent of mothers agreed for the teacher to be sent a questionnaire, and $91 \%$ of these were returned. Groups differed significantly in the proportions of parents consenting to teacher contact, $\chi^{2}(2, \mathrm{~N}=69)=16.74, p<.001$. Ninety-three per cent of IVF and $83 \%$ of adoptive mothers agreed, compared to $41 \%$ of embryo donation mothers. Mothers who allowed teacher contact were compared with those who refused on the variables from the mothers' interviews and questionnaires, and no significant differences were found.

The SDQ provides an overall score of the child's adjustment (total difficulties score), along with four subscales (hyperactivity, conduct problems, emotional difficulties and peer problems), where higher scores indicate greater difficulties. In addition, each subscale has a designated cut-off point above which the child is considered outside the normal range for the specific behaviour. Validity of the SDQ is demonstrated by high correlations with the Rutter Parent Questionnaire, $r=0.88$ (Rutter, Tizard, \& Whitmore, 1970), and the Rutter Teacher 
Questionnaire, $r=0.92$ (Rutter, 1967). The SDQ discriminates well between psychiatric and non-psychiatric samples.

\section{Disclosure of method of family creation}

An additional section of the mothers' interview focused on their disclosure to their child of the method of family creation. Mothers were asked whether or not they had already told their child about their assisted conception or adoption. Since the children's ages differed, and parents may delay disclosure until they feel the child is able to understand, mothers who had not already disclosed were asked if they intended to do so at a later date. Mothers' responses were coded into one of four categories: i) already told child; ii) intending to tell child in future; iii) undecided about telling child; and iv) definitely decided not to tell child.

\section{Results}

Initial analyses found that the interview variables and the marital and psychological state questionnaires were approximately normally distributed (except frequency of disputes which required transformation). Hence, group comparisons were made using analyses of covariance (ANCOVAs) and multivariate analyses of covariance (MANCOVAs). Where a significant result was found, individual contrast analyses were conducted: (1) Embryo Donation vs. Adoptive Families [ED vs. AD], which examined the differences between non-genetic families where the parents have a gestational link to their child, and those with no gestational link; and (2) Embryo Donation vs. IVF families [ED vs. IVF], which examined the differences between non-genetic and genetically related ART families. Since multiple comparisons were involved, Bonferonni corrections were applied $(p<.025)$. Power analysis was conducted using the $\mathrm{G}$ *Power 3 computer program (Faul, Erdfelder, Lang, \& Buchner, 2007), and power for individual contrasts for a medium effect size was found to be 66 . Where the family had twins, information was obtained about both children. To avoid interdependence of data one twin was included in data analysis at random. Analyses were 
then repeated using the second twin's data. This second analysis produced identical results, therefore only the first is reported.

\section{Mothers’ Marital and Psychological State}

According to separate ANCOVAs, mothers' marital satisfaction, parenting stress, anxiety and depression did not differ statistically between groups (see Table 1). Inspection of means showed a medium-sized absolute difference between group means for the GRIMS (maximum $\approx 0.5 \mathrm{SD}$ ), with the IVF mothers reporting lowest marital satisfaction and the embryo donation mothers reporting highest. However, the means for all three groups were within the normal range.

\section{Quality of Parenting}

Parenting variables were divided into two categories; parental warmth and parental control. Warmth

The variables relating to parental warmth were mother's enjoyment in play, enjoyment in motherhood, expressed warmth and sensitive responding. Principal components analysis (PCA) was conducted and all four variables loaded onto one component with loadings ranging from 0.61-0.80 (components with eigenvalues $<1.0$ were excluded, leaving only one extracted component). A MANCOVA was conducted and Pillai's trace was not significant, indicating no overall group difference in the level of maternal warmth. The size of differences between the group means was largest for the enjoyment of play (maximum $\approx$ $0.7 \mathrm{SD}$ ) and sensitive responding variables (maximum $\approx 0.5 \mathrm{SD}$ ), on both of which the embryo donation mothers' ratings were highest. However, mothers in all three groups obtained high mean scores on all warmth variables (see Table 2).

\section{Control}

Using PCA as above, overall supervision whilst playing out, chaperonage and emotional over-involvement loaded onto one component (supervision/involvement), with loadings 
ranging from 0.50-0.92, and ease of bedtime, frequency of disputes, and level of battle on a second component (disciplinary interactions), with loadings ranging from 0.57-0.77 (components with eigenvalues $<1.0$ were excluded, resulting in two extracted components).

Supervision/involvement. A MANCOVA was performed on these variables and Pillai's trace was significant, $F(6,126)=2.63, p<.025$, indicating an overall group difference (see table 2). The partial eta squared value for the group factor was .15, indicating that $15 \%$ of the variability in the dependent variables is attributable to family type. Individual contrast analyses found a statistical difference in emotional over-involvement. Embryo donation mothers were significantly more emotionally over-involved with their child than adoptive mothers [ED vs. AD], $t=2.40, p<.025$, Cohen's $d=0.80$. The contrast between embryo donation and IVF mothers [ED vs, IVF] was not significant, but the trend was in the same direction since the mean for embryo donation mothers was higher. Contrasts for overall supervision whilst playing out and chaperonage were not significant; the majority of parents were providing high levels of supervision and appropriate chaperonage.

Disciplinary interactions. The variables comprising the disciplinary interactions component were entered into a MANCOVA and Pillai's trace was not significant, indicating no overall difference between family types (see table 2). The magnitude of the differences between the means was relatively small for all of the group comparisons, with the largest being for frequency of disputes (maximum $\approx 0.3 \mathrm{SD}$ ).

\section{Children's socio-emotional adjustment}

The teachers' SDQ scores were found not to be normally distributed, maybe due to the reduced sample size. Therefore, non-parametric analyses were conducted. To allow for direct comparisons between the two, mothers' SDQ scores were also analysed non-parametrically. Groups were compared on each of the four subscales and the total difficulties score of the SDQ, independently for mothers and teachers. 


\section{Mothers}

Analyses showed a significant group difference for the hyperactivity subscale, (KruskalWallis test, $\mathrm{H}=9.42, \mathrm{p}<.01)$. The mean ranking for adopted children was higher than for embryo donation children. No group differences were found for total difficulties, conduct, emotional, or peer problems. However, both the total difficulties score and the peer problems subscale approached significance $(p<.10)$. The mean scores (see table 3 ) show that adopted children scored higher than embryo donation and IVF children on these two scales.

Chi-square analyses were used to test if a greater than expected proportion of adopted children exceeded the cut-off points for total difficulties, hyperactivity and peer problems. Goodman (1997) reported that approximately $20 \%$ of children in a community sample would be expected to exceed the SDQ borderline cut-offs. Chi-square was significant for total difficulties, $\chi^{2}(2, \mathrm{~N}=56)=7.88, \mathrm{p}<.025$; and hyperactivity, $\chi^{2}(2, \mathrm{~N}=56)=10.14, p<.01$. Twenty-nine percent $(n=5)$ of adopted children were rated as above cut-off for total difficulties, compared to $2(13 \%)$ embryo donation children and no IVF children. Similarly, $35 \%(n=6)$ of adopted children were rated as scoring above the hyperactivity cut-off, compared to $2(13 \%)$ embryo donation children and no IVF children. No significant differences were found for peer problems.

\section{Teachers}

The teachers' data generally supports that of mothers. Significant group differences were found using the Kruskal-Wallis test for the hyperactivity subscale $(\mathrm{H}=8.24, p<.025)$, with the mean ranks of adopted children being higher than those of embryo donation children. The group difference for the total difficulties score approached significance $(p<.10)$, and as for mothers' ratings, the mean scores were highest for adopted children and lowest for embryo donation children. Using chi-square analyses, significant differences were found in the proportion of children in each group scoring above cut-off for total difficulties, $\chi^{2}(2, N=48)$ 
$=11.32, p<.01$; and hyperactivity, $\chi^{2}(2, \mathrm{~N}=48)=8.82, p<.025$, but not for peer problems. Teachers rated $42 \%(n=8)$ of adopted children as having a borderline/abnormal total difficulties score, compared to no embryo donation children and 1 (4\%) IVF child. They also rated $47 \%(n=9)$ of the adopted children as having problems with hyperactivity, compared to no embryo donation children and $3(13 \%)$ IVF children.

\section{Disclosure of method of family creation}

Only three (18\%) of the 17 embryo donation mothers had told their child about the donor conception, with four mothers (24\%) stating that they planned to tell in the future. In contrast, $46 \%(n=13)$ of IVF mothers had disclosed to their child about the assisted conception, with a further $43 \%(n=12)$ reporting that they were planning to tell, and all of the adoptive parents had already told their child about the adoption, $\chi^{2}(2, \mathrm{~N}=69)=45.62, p<.001$. Two $(12 \%)$ of the embryo donation mothers and two (7\%) of the IVF mothers were undecided, and $47 \%(n=8)$ of embryo donation mothers had decided that they would not disclose this information to their child, whereas only one IVF parent had made this decision.

\section{Discussion}

The findings are in line with those of the earlier study, suggesting that embryo donation families are generally functioning well, with psychologically well-adjusted parents forming warm relationships with their non-genetic child. The children conceived through embryo donation do not show raised levels of emotional or behavioural problems in middle childhood. In contrast, the adopted children are rated by both mothers and teachers as demonstrating elevated rates of socio-emotional difficulties, specifically hyperactivity. The better adjustment of embryo donation compared to adopted children implies that that adoptees' problems stem not from being reared by non-genetic parents per se, but from characteristics peculiar to adoption. From a biological perspective, birth parents of adopted children may be more prone to genetically based psychological difficulties, with children 
inheriting this increased susceptibility (Brodzinsky et al., 1998). There is no reason to expect similar raised vulnerabilities in embryo donation families. Additionally, adopted children are at higher probability of experiencing non-optimal prenatal environments, with possible exposure to maternal alcohol or drugs abuse, poor maternal nutrition, and inadequate provision of antenatal care (Brodzinsky et al., 1998). Post birth, the pre-placement circumstances of the adopted child, which may include abuse and neglect by caregivers, could have negative consequences. The importance of pre-adoption experiences is supported by the findings from Simmel et al. (2001) that increased levels of ADHD symptoms in adoptees are closely associated with factors such as prior abuse and prenatal alcohol exposure. Similar problems do not arise in embryo donation families due to the gestational link; the couple control the prenatal environment, and rear the child from birth.

It is also possible that the adjustment problems exhibited by some adopted children are connected to their growing awareness of being adopted, and the understanding of having been relinquished by their birth parents (Brodzinsky et al., 1998). This may not be seen in embryo donation children due to the low levels of disclosure of the child's origins. Only $41 \%$ of embryo donation parents had already disclosed to their child or were intending to do so, in comparison to all of the adoptive parents and around $90 \%$ of the IVF parents. Embryo donation parents' attitudes resemble those in a recent study of donor insemination parents where $46 \%$ reported planning to disclose to their child (Golombok, Lycett et al., 2004). However, all 4 of the non-participating embryo donation couples from the first phase had stated that they were not going to tell. Subsequently, the proportion of disclosing embryo donation parents in this study may be higher than would be found in the general population, with those preferring non-disclosure less likely to participate. Therefore, embryo donation parents may even be more private about this issue than are other gamete donation parents. Despite the concerns regarding secrecy about donor conception (Daniels \& Taylor, 1993), 
there do not seem to be adverse effects at this stage. Interestingly, it did not seem that the 2005 legislation change had encouraged parents towards disclosure. Indeed, in the initial study, 5 sets of embryo donation parents reported planning to disclose, but only one had done so by the follow-up. This is in line with earlier findings that couples' reported disclosure intentions are not always reflected in their future actions (Golombok et al., 2002).

The lack of psychological problems in embryo donation children may be related to the quality of parenting. Maternal warmth and sensitivity are high in all three family types, and therefore negative effects on attachment would not be expected (Ainsworth et al., 1978). In addition, mothers in all three groups were generally providing appropriate levels of discipline and supervision. Parenting styles which combine high warmth and firm control in this way have been associated with positive social adjustment for children (Baumrind, 1989). As in the first phase of the study (MacCallum et al., 2007), the findings demonstrate that the lack of genetic relationships in embryo donation families does not result in less positive parenting than in IVF families. In fact, the embryo donation mothers obtained higher mean sensitive responding scores than the IVF mothers, although this finding was not statistically significant. Similarly, the quality of parenting was high in the adoptive families, despite the increased rates of child problems. Thus, these non-genetic parents are not exhibiting the lack of investment in their child hypothesised by evolutionary psychology (Bjorklund et al., 2002). Previous research on gamete donation families (Brewaeys, 2001; Golombok, Lycett et al., 2004) and adoptive families (Hoopes, 1982; Plomin \& DeFries, 1985) has also found no evidence for negative consequences of the absence of genetic links on parenting. It seems that the intense wish to rear a child, demonstrated by both embryo donation and adoptive parents in their dedication to achieving parenthood, prevails over any potential challenges of bonding to a non-genetic child. 
The lack of differences in warmth and sensitivity found between embryo donation and adoptive mothers further indicate that prenatal attachments (Laxton-Kane \& Slade, 2002) do not necessarily promote higher quality parenting. Adoptive parents have to undertake a lengthy and detailed selection process before having a child placed with them (Widdows \& MacCallum, 2002). One possibility is that the potential adopters who are successful are those who are particularly well-equipped to overcome the disadvantage of lacking a gestational link to their child. However, studies of surrogacy families have found that non-gestational mothers who have not been through the adoption process similarly demonstrate high levels of warmth towards their children (Golombok, Murray, Jadva, MacCallum, \& Lycett, 2004). Thus, an alternative explanation is that for these mothers, the social component of the role of motherhood compensates for not having carried the pregnancy.

Embryo donation mothers did exhibit significantly higher levels of emotional overinvolvement than adoptive mothers, similar to the findings of the first phase of the study. Furthermore, the mean rating for emotional over-involvement was higher for embryo donation mothers than for IVF mothers, although this difference was not statistically significant. Previous studies have observed tendencies towards over-involved parenting in mothers of children conceived through assisted reproduction (Gibson, Ungerer, Tennant, \& Saunders, 2000; Golombok et al., 2002), and in adoptive parents (Hoopes, 1982), which have been attributed to the stresses encountered in both the experience of infertility, and the adoption or assisted reproductive process. The embryo donation couples had experienced a longer average period of infertility prior to parenthood than either of the other two groups, and had generally undergone more cycles of infertility treatment than the IVF couples. This may leave them particularly prone to involving themselves as much as possible when the child finally arrives, and wanting to do as much with their child as they can. This desire to spend time with their child might account for embryo donation mothers reporting high 
average levels of enjoyment from mother-child leisure activities. Although emotional overinvolvement can be seen as a negative parenting trait (Thomasgard \& Metz, 1993), the mean ratings for embryo donation mothers did not represent pathological over-involvement, but rather moderate to low levels notable mostly for being significantly higher than the other groups. Furthermore, as in previous research (Gibson et al., 2000; Golombok et al., 2002), increased levels of parental protectiveness were not found to be associated with higher rates of child psychological problems. It seems that for embryo donation families, following their strenuous attempts to conceive, family life and parents' attention is more child-centred, but this is not necessarily adversely affecting the child. In addition, it should be noted that the analysis found only a small amount of the variance in emotional over-involvement accounted for by family type, suggesting that many other factors are at work.

The current study is limited in its generalisibility by the small size of the sample of embryo donation families which also reduces the statistical power of the analyses. To a certain degree this was unavoidable, due to the infrequent use of embryo donation. Initial recruitment was conducted through four clinics in different regions of the country to try to obtain the most representative sample possible and the cooperation rate for families was moderate to high. Nonetheless, it is not known how those families who refused to participate were faring. Furthermore, although the families who dropped out between first contact and follow-up were no different from other families at the initial study, non-participants may have been experiencing problems at this later stage. The relatively low power $(0.66)$ means there is a $34 \%$ chance of failing to find a difference between groups when such a discrepancy does actually exist. Inspection of the means indicated some medium-sized group differences which did not reach statistical significance, although none of these were in a direction that indicated problems for embryo donation families. Replication of the study with a larger sample is needed to increase validity of the findings. 
Parents who have conceived through ARTs are often concerned about the stigma attached to these techniques. Therefore, parental self-reports may be prone to social desirability bias, trying to present their family in the best possible light. Attempts were made to combat this by using multiple measures and by rating variables using strictly defined criteria. The original plan was to also interview fathers, allowing further exploration of the validity of the mothers' reports, but limited economic and time resources made this impractical. Only one visit was possible to each family, and mothers often preferred this to take place during the day when the majority of fathers were at work. It was then hoped that children's teachers could provide an independent source of information. Unfortunately, few embryo donation mothers gave permission to contact teachers. Comparisons of mothers who allowed teacher contact with those who declined did not show any differences on the measures of maternal marital and psychological state, children's development, or of quality of parenting. This suggests that mothers' refusal of teacher contact is due to an increased tendency towards privacy rather than to these families suffering increased difficulties. It was encouraging in terms of validity that where teachers' data was collected, the reports echo those of the mothers.

A further potential source of bias stems from the fact that one researcher conducted all interviews. Since the interview involved questions concerning the method of family creation, this interviewer could not be blind to family type. However, the researcher was fully trained on objective interviewing and adhered to detailed coding criteria. A proportion of interviews were rated by a second researcher with extensive experience in this field, and inter-rater reliabilities were all at least substantial.

Overall, these findings of this exploratory study do not seem to confirm concerns raised about embryo donation families. However, the increased emotional over-involvement, and secrecy about the method of conception, could have negative consequences later in life, particularly in adolescence when issues of autonomy and identity become more salient 
(Coleman \& Hendry, 1999). Research studying embryo donation families with older offspring would be valuable in addressing this. The fact that parenting in embryo donation families was no more positive than in adoptive families, and no less positive than in IVF families, suggests the possibility that neither genetic links nor gestational links are essential components of parenthood. Instead, what seems to be important is a strong commitment to parenting, and a desire to fulfil the social, nurturing role that parents play in their children's lives.

\section{References}

Abidin, R. (1990). Parenting Stress Index Test Manual. Charlottesville, VA: Pediatric Psychology Press.

Ainsworth, M., Bleher, M., Waters, E., \& Wall, S. (1978). Patterns of attachment: A psychological study of the Strange Situation. Hillsdale, NJ.: Erlbaum.

American Society for Reproductive Medicine (2008). Frequently asked questions about infertility. Retrieved February 8, 2008, from http://www.asrm.org/Patients/faqs.html

Baran, A., \& Pannor, R. (1993). Lethal Secrets (2nd ed.). New York: Amistad.

Baumrind, D. (1989). Rearing competent children. In W. Damon (Ed.), Child Development Today and Tomorrow (pp. 349-378). San Francisco: Jossey-Bass.

Bjorklund, D. F., Younger, J. L., \& Pellegrini, A. D. (2002). The evolution of parenting and evolutionary approaches to childrearing. In M. Bornstein (Ed.), Handbook of Parenting (Vol. 2, pp. 3-30). Mahwah, NJ: Lawrence Erlbaum Associates.

Bowlby, J. (1988). A secure base: Clinical applications of attachment theory. London: Routledge.

Brand, A. E., \& Brinich, P. M. (1999). Behavior problems and mental health contacts in adopted, foster, and nonadopted children. Journal of Child Psychology and Psychiatry, 40(8), 1221-1229. 
Brewaeys, A. (2001). Review: Parent-child relationships and child development in donor insemination families. Human Reproduction Update, 7(1), 38-46.

Brodzinsky, D., Smith, D. W., \& Brodzinsky, A. B. (1998). Children's adjustment to adoption. Developmental and clinical issues. (Vol. 38). London: Sage Publications.

Burns, L. H. (1990). An exploratory study of perceptions of parenting after infertility. Family Systems Medicine, 8, 177-189.

Carey, W. B., Lipton, W. L., \& Myers, R. A. (1974). Temperament in adopted and foster babies. Child Welfare, 53, 352-359.

Coleman, J. C., \& Hendry, L. (1999). The nature of adolescence (3rd ed.). London, UK: Routledge.

Cox, J. L., Holden, J. M., \& Sagovsky, R. (1987). Detection of postnatal depression: Development of the 10-item Edinburgh Postnatal Depression Scale. British Journal of Psychiatry, 150, 782-786.

Daniels, K., \& Taylor, K. (1993). Secrecy and openness in donor insemination. Politics and Life Sciences., 12(2), 155-170.

De Wolff, M., \& van IJzendoorn, M. H. (1997). Sensitivity and attachment: A meta-analysis on parental antecedents of attachment. Child Development, 68(4), 571-591.

Faul, F., Erdfelder, E., Lang, A.-G., \& Buchner, A. (2007). G*Power 3: A flexible statistical power analysis program for the social, behavioral, and biomedical sciences. Behavior Research Methods, 39, 175-191.

Gibson, F. L., Ungerer, J. A., Tennant, C. C., \& Saunders, D. M. (2000). Parental adjustment and attitudes to parenting after in vitro fertilization. Fertility and Sterility, 73(3), 565574. 
Golombok, S., Brewaeys, A., Giavazzi, M., Guerra, D., MacCallum, F., \& Rust, J. (2002). The European study of assisted reproduction families: The transition to adolescence. Human Reproduction, 17(3), 830-840.

Golombok, S., Lycett, E., MacCallum, F., Jadva, V., Murray, C., Abdalla, H., et al. (2004). Parenting children conceived by gamete donation. Journal of Family Psychology, 18(3), 443-452.

Golombok, S., Murray, C., Jadva, V., MacCallum, F., \& Lycett, E. (2004). Families created through a surrogacy arrangement: Parent-child relationships in the first year of life. Developmental Psychology, 40(3), 400-411.

Goodman, R. (1994). A modified version of the Rutter Parent Questionnaire including extra items on children's strengths: A research note. Journal of Child Psychology and Psychiatry, 35(8), 1483-1494.

Goodman, R. (1997). The Strengths and Difficulties Questionnaire: A research note. Journal of Child Psychology and Psychiatry, 38, 581-586.

Graham, P., \& Rutter, M. (1968). The reliability and validity of the psychiatric assessment of the child: II. Interview with the parent. British Journal of Psychiatry, 114, 581-592.

HFEA. (2005). Infertility - the real issues [Electronic Version]. HFEA - Parliamentary Briefing Newsletter. Retrieved 07/08/2007 from http://www.hfea.gov.uk/docs/Infertility_Final_(2).pdf.

Hoopes, J. L. (1982). Prediction in child development: A longitudinal study of adoptive and nonadoptive families. New York: Child Welfare League of America.

Laxton-Kane, M., \& Slade, P. (2002). The role of maternal prenatal attachment in a woman's experience of pregnancy and implications for the process of care. Journal of Reproductive and Infant Psychology, 20(4), 253-266. 
Levy-Shiff, R., Goldshmidt, I., \& Har-Even, D. (1991). Transition to parenthood in adoptive families. Developmental Psychology, 27(1), 131-140.

MacCallum, F., Golombok, S., \& Brinsden, P. (2007). Parenting and child development in families with a child conceived by embryo donation. Journal of Family Psychology, 21(2), 278-287.

Mahowald, M. B. (2000). Genes, women and equality. Oxford: Oxford University Press.

Muller, M. E. (1996). Prenatal and postnatal attachment: a modest correlation. Journal of Obstetric, Gynaecologic and Neonatal Nursing, 25, 161-166.

Murray, C., \& Golombok, S. (2003). To tell or not to tell: the decision-making process of egg donation parents. Human Fertility, 6, 89-95.

OPCS and Employment Department Group. (1991). Standard Classification of Occupations. London: HMSO.

Plomin, R., \& DeFries, J. (1985). Origins of individual differences in infancy: The Colorado Adoption Project. Orlando, FL: Academic.

Quinton, D., \& Rutter, M. (1988). Parenting Breakdown: The making and breaking of intergenerational links. Aldershot, UK: Avebury Gower Publishing.

Rust, J., Bennum, I., Crowe, M., \& Golombok, S. (1988). The Golombok Rust Inventory of Marital State (GRIMS). In D. Milne (Ed.), Assesment: A mental Health Portfolio: NFER-NELSON.

Rust, J., Bennun, I., \& Golombok, S. (1990). The GRIMS: A psychometric instrument for the assessment of marital discord. Journal of Family Therapy, 12, 45-57.

Rutter, M. (1967). A childrens' behaviour questionnaire for completion by teachers: preliminary findings. Journal of Child Psychology and Psychiatry, 8, 1-11.

Rutter, M., Tizard, J., \& Whitmore, K. (1970). Education, health and behaviour. London: Longman. 
Simmel, C., Brooks, D., Barth, R. P., \& Hinshaw, S. P. (2001). Externalizing symptamology among adoptive youth: Prevalence and preadoption risk factors. Journal of Abnormal Child Psychology, 29(1), 57-69.

Singer, L., Brodzinsky, D., Ramsay, D., Steir, M., \& Waters, E. (1985). Mother-infant attachment in adoptive families. Child Development, 56, 1543-1551.

Singer, L., Brodzinsky, D. M., \& Braff, A. M. (1982). Children's beliefs about adoption: A developmental study. Journal of Applied Developmental Psychology, 3, 285-294.

Spielberger, C. (1983). The Handbook of the State-Trait Anxiety Inventory. Palo Alto, CA: Consulting Psychologists Press.

Steptoe, P. C., \& Edwards, R. G. (1978). Birth after reimplantation of a human embryo. The Lancet, 2, 366.

Thomasgard, M., \& Metz, W. P. (1993). Parental Overprotection Revisited. Child Psychiatry and Human Development, 24(2), 67-81.

Thorpe, K. (1993). A study of the use of the Edinburgh postnatal depression scale with parent groups outside the postpartum period. Journal of Reproductive and Infant Psychology, $11,119-125$.

Triseliotis, J., Shireman, J., \& Hundleby, M. (1997). Adoption: Theory, policy and practice. London: Redwood Books.

van Balen, F. (1996). Child-rearing following in vitro fertilization. Journal of Child Psychology and Psychiatry, 37(6), 687-693.

Widdows, H., \& MacCallum, F. (2002). Disparities in parenting criteria: An exploration of the issues, focusing on adoption and embryo donation. Journal of Medical Ethics, 28, $139-142$. 
Tables

Table 1: Means, Standard Deviations and F values for comparisons of Parents' Marital and Psychological State by Family Type

\begin{tabular}{|c|c|c|c|c|c|c|c|c|}
\hline \multirow{2}{*}{ Variable } & \multicolumn{2}{|c|}{$\mathrm{ED}(\mathrm{N}=13)$} & \multicolumn{2}{|c|}{$\mathrm{AD}(\mathrm{N}=16)$} & \multicolumn{2}{|c|}{$\operatorname{IVF}(\mathrm{N}=24)$} & \multirow[b]{2}{*}{$F$} & \multirow[b]{2}{*}{$p$} \\
\hline & M & SD & M & SD & M & $\mathrm{SD}$ & & \\
\hline GRIMS & 20.91 & 10.23 & 24.81 & 12.08 & 26.60 & 10.55 & 0.86 & ns \\
\hline PSI & 64.69 & 25.42 & 65.25 & 13.51 & 61.92 & 12.10 & 1.42 & ns \\
\hline EDS & 6.08 & 4.91 & 5.38 & 4.49 & 5.54 & 4.89 & 0.05 & ns \\
\hline TAI & 36.62 & 11.04 & 36.69 & 8.56 & 37.04 & 9.61 & 0.12 & $n s$ \\
\hline
\end{tabular}

Note. $\mathrm{ED}=$ Embryo donation; $\mathrm{AD}=$ adoptive; GRIMS = Golombok Rust Inventory of Marital State; PSI = Parenting Stress Index; EDS = Edinburgh Depression Scale; TAI = Trait Anxiety Inventory 
Table 2: Means, Standard Deviations, and $F$ values for Comparison of Parenting Quality by Family Type

\begin{tabular}{|c|c|c|c|c|c|c|c|c|c|}
\hline \multirow{2}{*}{ Variable } & \multicolumn{2}{|c|}{$\mathrm{ED}(\mathrm{N}=17)$} & \multicolumn{2}{|c|}{$\operatorname{AD}(\mathrm{N}=24)$} & \multicolumn{2}{|c|}{$\operatorname{IVF}(\mathrm{N}=28)$} & \multirow[b]{2}{*}{$F$} & \multicolumn{2}{|c|}{ Contrasts } \\
\hline & M & $\mathrm{SD}$ & M & $\mathrm{SD}$ & M & SD & & $\begin{array}{c}\text { ED vs. } \\
\text { AD }\end{array}$ & $\begin{array}{c}\text { ED vs. } \\
\text { IVF }\end{array}$ \\
\hline & \multicolumn{4}{|c|}{ Mother's Warmth } & & & 1.23 & & \\
\hline Enjoyment of play & 2.82 & 0.39 & 2.42 & 0.58 & 2.54 & 0.58 & & & \\
\hline $\begin{array}{l}\text { Enjoyment in } \\
\text { motherhood }\end{array}$ & 2.88 & 0.33 & 2.75 & 0.44 & 2.93 & 0.26 & & & \\
\hline Expressed warmth & 4.53 & 0.51 & 4.38 & 0.58 & 4.57 & 0.50 & & & \\
\hline \multirow[t]{2}{*}{ Sensitive responding } & 3.41 & 0.62 & 3.17 & 0.87 & 3.04 & 0.74 & & & \\
\hline & \multicolumn{4}{|c|}{ Supervision/involvement } & & & $2.63 *$ & & \\
\hline Supervision & 1.00 & 0.79 & 0.67 & 0.70 & 0.43 & 0.74 & & $n s$ & ns \\
\hline Chaperonage & 2.76 & 0.56 & 2.46 & 0.72 & 2.36 & 0.62 & & ns & ns \\
\hline \multirow[t]{2}{*}{ Over-involvement } & 1.35 & 0.93 & 0.67 & 0.76 & 0.86 & 0.65 & & $<.025$ & ns \\
\hline & \multicolumn{4}{|c|}{ Disciplinary interactions } & & & 1.18 & & \\
\hline Ease of bedtime & 0.53 & 0.72 & 0.75 & 0.61 & 0.68 & 0.61 & & & \\
\hline Frequency of disputes & 32.47 & 35.32 & 41.21 & 40.62 & 28.23 & 33.75 & & & \\
\hline Level of battle & 1.35 & 0.79 & 1.46 & 0.78 & 1.5 & 0.69 & & & \\
\hline
\end{tabular}

Note. $\mathrm{ED}=$ embryo donation; $\mathrm{AD}=$ adoptive

$* p<0.01$ 
Table 3: Means, Standard Deviations and Kruskal-Wallis test values for comparisons of SDQ scores by Family Type

\begin{tabular}{llllllllll}
\hline SDQ subscale & M & SD & M & SD & M & SD & H & $p$
\end{tabular}

Mother-rated

$$
\operatorname{ED}(\mathrm{N}=15) \quad \operatorname{AD}(\mathrm{N}=17) \quad \operatorname{IVF}(\mathrm{N}=24)
$$

Hyperactivity

$1.93 \quad 2.89$

$4.30 \quad 2.97$

2.13

1.36

$9.42<.01$

Conduct problems

$\begin{array}{llll}1.40 & 1.92 & 1.94 & 2.16\end{array}$

1.13

1.23

1.07 ns

Emotional symptoms

1.33

2.13

$1.88 \quad 2.52$

1.33

1.27

$.60 \quad n s$

Peer problems

$\begin{array}{llll}0.80 & 1.37 & 2.24 & 2.49\end{array}$

$1.08 \quad 1.50$

$5.14<.10$

Total difficulties

$\begin{array}{llll}5.47 & 6.38 & 10.47 & 9.08\end{array}$

5.67

3.24

$5.53<.10$

Teacher-rated

\begin{tabular}{lcccccccc} 
& \multicolumn{2}{c}{$\mathrm{ED}(\mathrm{N}=6)$} & $\mathrm{AD}(\mathrm{N}=19)$ & \multicolumn{2}{c}{ IVF $(\mathrm{N}=23)$} & & \\
Hyperactivity & 0.83 & 1.33 & 4.62 & 3.45 & 2.17 & 2.35 & 8.24 & $<.025$ \\
Conduct problems & 0.67 & 1.63 & 1.26 & 2.08 & 0.26 & 0.69 & 2.99 & $n s$ \\
Emotional symptoms & 0.67 & 1.21 & 1.58 & 1.89 & 1.26 & 1.84 & 1.46 & $n s$ \\
Peer problems & 0.50 & 0.55 & 1.53 & 1.93 & 1.30 & 1.55 & .89 & $n s$ \\
Total difficulties & 2.67 & 3.44 & 9.00 & 7.54 & 5.00 & 3.91 & 4.75 & $<.10$
\end{tabular}

Note. $\mathrm{ED}=$ Embryo donation; $\mathrm{AD}=$ adoptive 